BEIJING INTERNATIONAL REVIEW OF EDUCATION
$1(2019) 579-583$

\title{
New Curricular Standards of Senior High Schools in China
}

\author{
Yanyan Ji \\ College of Teacher Education, Zhejiang Normal University \\ 2877679461@qq.com \\ Yanjun Zhang \\ College of Teacher Education, Zhejiang Normal University \\ yjzhang7661@163.com
}

\begin{abstract}
China has embarked on a new wave of curriculum reform since 2018. New Curricular Standards attempts to reposition high schools with the aim of improving the quality of citizens nationwide. It repositions basic education for the public which shall not only prepare students for university, but also for students to adapt to social life and career development, thus laying a foundation for their whole-life development. Emphasizing the key competence that students are expected to possess and formulating the academic quality standards are the two major innovations in this reform.
\end{abstract}

\section{Keywords}

China watch - curriculum reform - senior high schools - new curricular standards China

\section{Introduction $^{1}$}

In recent years, many countries in the world have reformed school curriculum as a strategy to enhance their comprehensive strength. China is no exception

1 This article is co-authored with Ruyi Li (College of Foreign Languages, Zhejiang Normal University) and Tianyu Feng (Yiyuan No. 1 Senior High School), and funded by a research 
with a determined national goal to reform its basic education curriculum. In December 2017, the Ministry of Education (the MOE, hereafter) announced The Senior High School Curricular Plans and Standards (2017 ed.) for 20 subjects of senior higher schools. This new initiative aims to connect the examination reform with curriculum reform in secondary schools, and integrate teaching, examination and recruitment to promote the comprehensive and individualized student development (The MOE, 2017).

Education is viewed as a key process for student development, especially during the stage of senior secondary schools. The old curricular standards implemented in 2003 are no longer able to meet the new demand in the 21st century. For example, its updates have been slow, and the curriculum construction of new technologies lags behind, often failing to comply with demands of social development. The learning structure is unreasonable, and the differentiation of subject categories between "major" and "minor" easily neglects such subjects as Art, Music and Physical Education, which does not meet the expectation of quality education. Furthermore, overwhelmed subjects and exam-oriented approaches over burden students and often discourage their learning interests. The old curriculum standards did not set clear requirements for the extent to which students must learn, making it difficult for teachers to evaluation their learning outcomes (Yu, 2014). Such problems have called urgent reform for curriculum change.

The Initiative

2.1

Repositioning High School Education and Effectively Connecting College Entrance Examination Reform

Compared with the old curriculum plan of high schools in 2003, the new curriculum standards reposition senior high schools, optimizes their curriculum structure, and strengthens the effective implementation of the new curriculum. In view of the unilateral pursuit of university enrollment rates in the past, the reform underlines that senior high schools are to improve the quality of Chinese citizenry. At the same time, the reform increases the selectivity of subjects, and enhances the hierarchy, diversity and selectivity of subjects through multiple modules, so as to meet the needs of students' lifelong development and effectively connect with the new system of college entrance examination. In terms of the relationship between teaching and evaluation,

project (No.: FYZS201415) sponsored by the Institute of African Studies of Zhejiang Normal University. 
the current reform ensures that the curriculum is divided into three categories: compulsory subjects, selective compulsory subjects and elective subjects. These are deemed as suitable for the high school academic level examination and college entrance examination as well as for the development of students' interests and individualities. In the aspect of examination proposition, each subject has revised the evaluation objective and strengthened the evaluation of the key competences.

\subsection{Focus on "Core Qualities" and Building Academic Quality Standards}

Focusing on "Core Qualities" and building academic quality standards are two major structural changes in the new senior high school curriculum reform. The new standards emphasize the cultivation of students' core qualities in teaching. The teaching approach has evolved from "problem solving" to "project-based learning", and the requirements for students have changed from "learning to learn independently" to "strengthening inquiry-based learning". In line with the development of the world, it guides students to comprehensively improve the "Core Qualities" and develop lifelong learning habits (Wang, 2018). With a focus on "Core Qualities" of high school students, new academic quality standards must be created, a new quality concept must be established, the degree of knowledge and skills expected in the past must be changed, and teaching should be guided to pay more attention to the purpose of education.

In terms of curriculum structure, the new curriculum standards emphasize the consistency with the 9-year compulsory education and gradual development of subjects, and stress the balance of subjects with different roles. In relation to curriculum objectives, instead of overemphasizing knowledge imparting, the new curriculum standards emphasize on more the achievement of the three-dimensional goals: knowledge and skills, process and methods, emotions and values.

With regards to curriculum contents, taking the "Core Qualities" of senior high school students as the guideline, the new standards emphasize on strengthening the connection between curriculum contents and real life so as to enable students to acquire more daily life skills. Pertaining to curriculum implementation, the new standards highlight the stimulation of students' interests, inviting students active participation in inquiry and cooperation with each other. As to curriculum evaluation, the new standards emphasize on establishing a system to promote students' all-round development and the improvement of teachers' teaching, and the purpose of evaluation should be changed from selection to the improvement of teaching and development. Lastly, in terms of curriculum management, the new standards integrate the three-level management systems respectively at national, regional and school 
levels, adjust measures to local conditions and more mobilize the enthusiasm of local and schools' participation as well as the pertinence of education.

\subsection{Carrying on the Legacy of Traditional Culture and Opening up to a Modern International Perspective}

The new curriculum standards strengthen education of Chinese culture and revolutionary tradition, and each subject is expected to combine its characteristics to enrich related contents. In particular, in the subject of Chinese literacy, traditional Chinese culture and revolutionary tradition are integrated into all elements of the curriculum. The curriculum reform also sets learning programs that students are required to learn a wide range of literature from ancient times up to the late Qing dynasty, and recite 72 classics. In addition to that, the new curriculum requires students to read famous poets by revolutionary forerunners and other masterpieces full of revolutionary zeal and spirit. All these endeavors aim to enhance cultural confidence and nurture patriotism through news reports, lectures and commentaries on revolutionary tradition.

Such foreign languages as French, German and Spanish are added to the curriculum of senior high schools, in addition to English, Japanese and Russian which have been set up in the old curriculum as implemented in 2003. The number of foreign languages offered as subjects are now doubled to a total of six. It is evident that the new curriculum reform opens up more windows and opportunities for students with a much broader international perspective. As the coverage of six languages is quite broad, the study of the foreign languages will help develop students' ability to understand and interact with the world, which will bring about a more internationalized perspective of the younger Chinese generation in the future.

\section{The Implementation}

It has been four years since the senior high school curricular plans and standards was initiated. In 2014, the MOE issued The Opinion on Deepening Curriculum Reform in an All-Around Way and Fulfilling the Fundamental Task of Moral Education, announcing a new round of curriculum reform in China. Later, the MOE conducted a research domestically and internationally, making and testing the key competencies of 20 curriculums from 2015 to 2016 and standardizing the different levels of key competence and academic quality, to meet the basic needs of all students at different development levels. In order to better making the new curriculum standards, the MOE set up a task force with over 260 experts, and held 16 plenary meetings to discuss the reform. It then tested 
whether the new curriculum standards were scientific and feasible in more than 40,000 students from 19 provinces or cities. In 2017, the National Teaching Materials Committee was established to review the new plans and standards. Through a series of revisions, the MOE formally enacted The Senior High School Curricular Plans and Standards (2017 ed.) on January 16, 2018, which has been officially implemented since the fall term in 2018.

The new curriculum reform is viewed by many as the largest and most fundamental education reform in China in recent years, which aims to a transformation of education targeting at the cultivation of individualized and comprehensive talents. However, the reform will not be accomplished overnight. In the future, teachers will have to continuously improve the curriculum implementation and deepen the reform on the basis of the previous reforms with teaching practices. Together with policymakers, they will lead senior high schools into a new stage and make meaningful contributions to modernize China's education.

\section{References}

The moe. (2017). The Senior High School Curricular Plans and Standards (2017 ed.). Retrieved from http://www.moe.gov.cn/srcsite/A26/s8001/201801/t20180115_324647 .html.

Wang, Y.F. (2018, January 17). Carry out tests on the core subject qualities to ensure the scientificity of curricular standards [Kaizhan xueke hexin suyang shice yanjiu, Quebao kebiao kexuexing]. Retrieved from http://www.moe.gov.cn/jyb_xwfb/xw_fbh/ moe_2069/xwfbh_2018n/xwfb_20180116/zjwz/201801/t20180117_324914.html.

Yu, H.J. (2014). Coordinating and promoting the work of moral education: Zheng Fuzhi, Director of the Department of Basic Education of the Ministry of Education, answered questions on comprehensively deepening the curricular reform. People's Education, 10, 10-12. 